The University of Maine

\title{
DigitalCommons@UMaine
}

Maine-Syracuse Longitudinal Papers

Maine-Syracuse Longitudinal Study

2014

\section{Higher HDL cholesterol is associated with better cognitive function: The Maine-Syracuse Study}

Georgina E. Crichton

University of South Australia

Merrill F. Elias

University of Maine,mfelias@maine.edu

Adam A. Davey

Temple University

Kevin J. Sullivan

University of Maine, kevin.sullivan@maine.edu

Follow this and additional works at: https://digitalcommons.library.umaine.edu/

longitudinal_papers

\section{Repository Citation}

Crichton, Georgina E.; Elias, Merrill F.; Davey, Adam A.; and Sullivan, Kevin J., "Higher HDL cholesterol is associated with better cognitive function: The Maine-Syracuse Study" (2014). Maine-Syracuse Longitudinal Papers. 61.

https://digitalcommons.library.umaine.edu/longitudinal_papers/61 


\title{
Higher HDL Cholesterol Is Associated with Better Cognitive Function: the Maine-Syracuse Study
}

\author{
Georgina E. Crichton, ${ }^{1,2}$ Merrill F. Elias, ${ }^{3,4}$ Adam Davey, ${ }^{5}$ Kevin J. Sullivan, ${ }^{3}$ AND Michael A. Robbins ${ }^{3,4}$ \\ ${ }^{1}$ Nutritional Physiology Research Centre, University of South Australia, Adelaide, Australia \\ ${ }^{2}$ Centre de Recherche Public Santé, Centre d'Etudes en Santé, Grand-Duchy of Luxembourg \\ ${ }^{3}$ Department of Psychology, University of Maine, Orono, Maine \\ ${ }^{4}$ Graduate School of Biomedical Science and Engineering, University of Maine, Orono, Maine \\ ${ }^{5}$ Department of Public Health, Temple University, Philadelphia, Pennsylvania
}

(Received May 23, 2014; Final Revision September 27, 2014; Accepted September 29, 2014; First Published OnLine November 10, 2014)

\begin{abstract}
Few studies have examined associations between different subcategories of cholesterol and cognitive function. We examined relationships between total cholesterol (TC), high-density lipoprotein cholesterol (HDL), low-density lipoprotein cholesterol (LDL), triglyceride levels and cognitive performance in the Maine-Syracuse Longitudinal Study, a community-based study of cardiovascular risk factors. Cross-sectional analyses were undertaken on data from 540 participants, aged 60 to 98 years, free of dementia and stroke. TC, HDL, LDL, and triglyceride levels were obtained. Cognitive function was assessed using a thorough neuropsychological test battery, including domains of cognitive function indexed by multiple cognitive tests. The cognitive outcomes studied were as follows: Visual-Spatial Memory and Organization, Verbal and Working Memory, Scanning and Tracking, Abstract Reasoning, a Global Composite score, and the Mini-Mental State Examination (MMSE). Significant positive associations were observed between HDL-cholesterol and the Global Composite score, Working Memory, and the MMSE after adjustment for demographic and cardiovascular risk factors. Participants with desirable levels of HDL ( $\geq 60 \mathrm{mg} / \mathrm{dL})$ had the highest scores on all cognitive outcomes. There were no significant associations observed between TC, LDL, or triglyceride concentrations and cognition. In older individuals, HDL-cholesterol was related to a composite of Working Memory tests and for general measures of cognitive ability when adjusted for cardiovascular variables. We speculate that persons over 60 are survivors and thus less likely to show cognitive deficit in relation to TC, LDL-cholesterol, and triglycerides. Longitudinal studies are needed to examine relations between specific cognitive abilities and the different subcategories of cholesterol. (JINS, 2014, 20, 961-970)
\end{abstract}

Keywords: Cognition, Cholesterol, Lipoproteins, HDL, LDL, Elderly

\section{INTRODUCTION}

Associations between cholesterol and cognitive function are not clearly understood. Understanding of this relationship is made difficult by the fact that cholesterol is vital for brain development and function (Dietschy \& Turley, 2004; Koudinov \& Koudinova, 2001); yet in excess some cholesterols are a risk factor for cardiovascular disease (CVD) (Hillbrand \& Spitz, 1997).

The liver produces 70 to $80 \%$ of the cholesterol and triglycerides in the body. Large lipoproteins, called very low density lipoproteins (VLDLs) carry cholesterol, triglycerides, and proteins called apolipoproteins. The density of the

Correspondence and reprint requests to: Georgina Crichton, Centre d'Etudes en Santé, CRP-Santé, 1 A rue Thomas Edison, L-1445, Strassen, Luxembourg. E-mail: georgina.crichton@mymail.unisa.edu.au lipoproteins refers to the ratio of the lipid to protein, that is, a high ratio corresponds to low density (Hillbrand \& Spitz, 1997). The VLDLs travel through the blood stream releasing triglycerides that provide energy to body tissues and are consequently stored as fat. VLDLs become cholesterol-rich low-density lipoproteins (LDL) as triglycerides are released. This lipid subfraction is received by specialized LDL receptors throughout the body for the manufacture and repair of cell membranes and for the synthesis of steroid hormones and bile acids. However, when receptor activity fails to meet LDL concentrations, levels of the latter increase and are deposited in the arteries, the atherosclerotic process, which may lead to heart disease, myocardial infarction and stroke. Elevated blood triglycerides have a dose-dependent association with cardiovascular-related and all-cause mortality (Liu et al., 2013). Thus LDL-cholesterol and triglycerides have been termed in lay terms as "bad cholesterol." 
In contrast, high-density lipoprotein cholesterol (HDL) is related to lower prevalence of cardiovascular mortality (Silbernagel et al., 2013) and incidence of coronary heart disease (Tehrani et al., 2013). HDL-cholesterol serves to remove excess cholesterol from the cells, and transports it back to the liver to be disposed through the bile, thereby preventing atherosclerosis and protecting the arteries (FelixRedondo, Grau, \& Fernandez-Berges, 2013), in addition to anti-inflammatory (Vaisar et al., 2007) and antioxidant effects (Elsoe et al., 2012). Therefore, the balance of LDL and HDL levels determines the degree of atherosclerotic plaque formation and subsequent disease (Felix-Redondo et al., 2013). Low HDL has been associated with decreased hippocampal volume, a particularly vulnerable area of the brain associated with neurodegenerative disease (Wolf et al., 2004). Hence HDL is referred to as "good cholesterol" (Hillbrand \& Spitz, 1997).

Based on these mechanisms, it could be predicted that total cholesterol (TC), LDL-cholesterol, and triglycerides (the "bad cholesterols") would be associated with lower levels of cognitive performance given that risk factors that raise the risk of heart disease and stroke are generally bad for cognition (Waldstein \& Elias, 2001, 2014). It may also be predicted that "good cholesterol," HDL-cholesterol, given its anti-atherogenic properties (Nofer et al., 2002), may be positively associated with cognitive performance. However, the neuropsychology literature indicates that these relations in the expected direction are not always observed.

A meta-analysis and review of 18 investigations examining cholesterol, dementia and cognitive decline, has indicated an association between high midlife TC and lower cognitive performance in late life (Anstey, Lipnicki, \& Low, 2008). Of five studies examining TC in relation to cognitive decline, Anstey et al. (2008) report that two found higher TC to be associated with a reduced risk of cognitive decline (Swan, Larue, Carmelli, Reed, \& Fabsitz, 1992; Wada et al., 1997), while the other three found no associations (Kalmijn, Feskens, Launer, \& Kromhout, 1996; Karlamangla, Singer, Reuben, \& Seeman, 2004; Reitz, Luchsinger, Tang, Manly, \& Mayeux, 2005).

However, prospective studies with the Framingham Heart Study (Elias, Elias, D'Agostino, Sullivan, \& Wolf, 2005) and the National Heart, Lung, and Blood Institute Twin Study (Swan et al., 1992) have indicated associations between increasing levels of TC and better cognitive performance. Elias and colleagues (2005) studied nearly 1900 Framingham Heart Study participants, free of dementia or stroke (mean age of 67). TC measured four to 6 years previously was positively related to attention and concentration, word fluency, similarities and composite performance but not learning or memory. Following adjustment for age, gender, education, alcohol and CVD, having TC below $200 \mathrm{mg} / \mathrm{dL}$ was associated with significantly higher odds for poor performance on the cognitive composite measure. Other studies have supported the Framingham findings; higher TC has been associated with better performance on tests of processing speed and mental flexibility (Benton, 1995; Muldoon,
Ryan, Matthews, \& Manuck, 1997; Swan et al., 1992). In analyses based on the third National Health and Nutrition Survey in over 4000 adults, higher TC was associated with faster reaction time in men (Zhang, Muldoon, \& McKeown, 2004). These findings indicate that higher serum cholesterol may be associated with greater processing speed or cognitive flexibility. Other studies have shown no association (Reitz et al., 2005; Romas, Tang, Berglund, \& Mayeux, 1999; Zimetbaum et al., 1992) or shown TC to be risk factor for lower cognitive performance and dementia (Desmond, Tatemichi, Paik, \& Stern, 1993; Notkola et al., 1998; Yaffe, Barrett-Connor, Lin, \& Grady, 2002). Two recent reviews underscore the inconsistent findings in the literature (Muldoon \& Conklin, 2014; Schreurs, 2010).

One of the major issues in relating TC levels to cognitive performance, and a possible reason for conflicting results may be that examination of TC ignores the contributions of the cholesterol components, for example, LDL, HDL, and triglycerides. Fewer studies have related the individual cholesterols to cognitive performance, and fewer yet have used a comprehensive test battery.

When LDL and triglycerides have been related to cognitive performance, conflicting results have emerged. Studies have reported that high levels of LDL-cholesterol may be associated with poorer cognitive performance (van den Kommer, Dik, Comijs, Jonker, \& Deeg, 2012), while others have shown no association (Romas et al., 1999; Singh-Manoux, Gimeno, Kivimaki, Brunner, \& Marmot, 2008; Yoshitake et al., 1995). Anstey et al. (2008) in their review, found no associations between LDL and cognitive performance, dementia or cognitive decline. Very few studies have specifically examined levels of triglycerides in relation to cognition (Reynolds, Gatz, Prince, Berg, \& Pedersen, 2010; Singh-Manoux et al., 2008). Singh-Manoux et al. (2008) found no association between triglycerides and verbal memory performance, while Reynolds et al. (2010) showed that lower triglyceride levels predicted better verbal ability and perceptual speed.

Given the positive association between HDL and heart health, it seems highly plausible that higher levels of HDL may relate in a positive manner to global cognitive performance. In the Whitehall II study, Singh-Manoux and colleagues (2008) examined lipoprotein lipid levels in relation to short term verbal memory change over five years in middleaged adults (mean age of 55 years at baseline). At two distinct time points, cross-sectional analyses showed positive associations between HDL and a single test of verbal memory, and furthermore, decline in HDL over the study period was associated with decline in verbal memory performance. As noted above, no significant associations were found between $\mathrm{TC}$ or triglycerides and verbal memory performance in this study (Singh-Manoux et al., 2008). However, only one measure of cognition was used in the study, verbal memory (indexed by only one test), so it is unknown whether general cognitive performance or other cognitive domains may have been affected by low HDL-cholesterol. In support, three other studies have showed a positive association between HDL measured in older age ( $\geq 50$ years) and cognition, including 
memory (van den Kommer et al., 2012), motor speed (Mielke et al., 2008), and verbal ability (Reynolds et al., 2008). In contrast, the review by Anstey et al. (2008) concluded that HDL was not associated with cognitive decline or impairment. However, they point out that the small number of studies reporting relevant data on HDL prevent strong conclusions being drawn with respect to these relations (Anstey et al., 2008). More studies of HDL and cognitive function are necessary and the essence of neuropsychology investigation is that domains be defined by multiple indices of cognitive performance.

Adding to the complexity of the relations between cholesterol and cognition, reviews by Anstey et al. (2008) and van Vliet (2012) indicate that associations between TC and cognitive decline or lowered cognitive performance may be age-dependent. The current literature suggests that high TC in mid-life is associated with elevated risk of poor memory and dementia late in life (Anstey et al., 2008), whereas when measured after age 60, high TC may not be associated with cognitive function or dementia risk, or may show a negative association (Anstey et al., 2008; van Vliet, 2012; van Vliet, Westendorp, van Heemst, de Craen, \& Oleksik, 2010). Despite the importance of relating mid-life cholesterol to late life cognitive performance, it is also important to know whether the individual cholesterols, and especially HDL, are related to cognitive performance after age 60 , and to investigate whether this is a global influence on cognition or more specific.

The purpose of this study was to investigate the relationship between TC, HDL- and LDL-cholesterol, and triglycerides with multiple cognitive domains in stroke and dementia-free individuals, 60 to 98 years of age, and to do so with and without adjustment for cardiovascular risk factors. A cross-sectional community-based sample from the Maine-Syracuse Longitudinal Study (MSLS) was used, with extensive data collected on multiple cardiovascular, lifestyle, and health factors.

Given the conflicting results for TC, HDL-, and LDLcholesterol, and relatively few studies of triglycerides in the literature, working hypotheses were generated based on hypothesized mechanisms rather than the literature. The study hypotheses were twofold: (1) higher LDL-cholesterol and triglycerides would be related to lower levels of cognitive performance; (2) higher HDL-cholesterol would be related to higher levels of cognitive performance. We also examined evidence for whether TC, LDL-, and HDL-cholesterol were simply proxies for absence of CVD. Thus we estimated two models, one with demographic risk factors and a second with added cardiovascular risk factors.

\section{METHODS}

\section{Participants}

Community-living individuals participating in the MaineSyracuse Longitudinal Study were recruited from central New York for studies of blood pressure, related risk factors, and cognitive performance with no exclusions other than institutionalization, diagnosed psychiatric disorder and alcoholism. Participants for the present study were those that returned for the sixth (2001-2006) study wave where extensive data on cardiovascular risk factors and diseases, including cholesterol values, were available for the first time (Elias et al., 2006; Robbins, Elias, Elias, \& Budge, 2005). Details of initial study recruitment have been previously described (Dore, Elias, Robbins, Budge, \& Elias, 2008; Elias et al., 2009, 2006; Robbins et al., 2005). Beginning with 574 individuals who met study criteria of at least 60 years of age, participants were excluded for the following reasons: acute stroke $(n=20)$, probable dementia $(n=9)$, and undertaking dialysis treatment $(n=5)$, leaving 540 individuals included in the final analyses. Acute stroke was defined as a focal neurological deficit persisting for $>24 \mathrm{hr}$ and probable dementia was defined by cognitive measures, medical records and a multidisciplinary dementia review using the National Institute of Neurological Diseases and Communicative Diseases and Stroke/ Alzheimer's Disease and Related Disorders (NINCDS-ADRDA) criteria (McKhann et al., 1984). Dementia cases were excluded as we were interested in examining relationships between cholesterol and cognitive performance, but not in those with severe cognitive impairment. This research was approved by the University of Maine Institutional Review Board and informed consent was obtained from all participants. All data in this study were obtained in compliance with the Helsinki Declaration.

\section{Procedure}

A blood sample was obtained following a fast from midnight with blood draw between approximately 8 and 9 AM. Standard assay methods were used (Elias et al., 2006) to obtain TC, HDL, LDL, and triglycerides, in addition to fasting plasma glucose, at Centrex Clinical Laboratories, New York. The direct HDL-cholesterol method for the Poly-ChemTM System, enzymatic elimination assay for the in vitro determination of HDL-cholesterol in human serum and plasma was used: Cat NO HDL500 (3×245 tests) Enzyme Reagent R1 $(3 \times 50 \mathrm{~mL})$; Enzyme Reagent R2 $(3 \times 20 \mathrm{~mL})$. Participants underwent a brief medical examination and interview after a light breakfast. Body weight was measured with participants wearing light clothing to the nearest $0.1 \mathrm{~kg}$, and height was measured with a vertical ruler to the nearest $0.1 \mathrm{~cm}$. Body mass index (BMI) was calculated as weight in kilograms divided by height in meters squared $\left(\mathrm{kg} / \mathrm{m}^{2}\right)$. Automated blood pressure measures (GE DINAMAP 100DPC-120XEN, GE Healthcare) were taken five times each in reclining, sitting and standing positions after a supine rest for $15 \mathrm{~min}$, and averaged for systolic and diastolic blood pressure. Smoking status (cigarettes smoked per week) was based on self-report from the Nutrition and Health Questionnaire (Kroke et al., 1999), as was alcohol consumption. Prevalent CVD was based upon self-reported history of coronary artery disease, myocardial infarction, congestive heart failure, transient ischemic attack, or angina 
pectoris, confirmed by medical records. Diabetes was defined as fasting glucose level of $\geq 126 \mathrm{mg} / \mathrm{dL}$, or being treated with anti-diabetic medication. Depressed mood was assessed using the Center for Epidemiologic Depression Scale (CES-D) (Radloff, 1977), and the raw score (number of symptoms) was used as a continuous variable. The foregoing measures were obtained during interview and physical examination during the morning visit, and cognitive measures were assed in the afternoon after at least a $1 \mathrm{hr}$ separation of the medical data collection and cognitive testing.

\section{Predictor variables: cholesterol}

As triglycerides were skewed, this variable was log transformed. All other lipoprotein variables were normally distributed. The predictor variables of interest were therefore HDL-cholesterol, LDL-cholesterol, triglycerides (log), and TC (all mg/dL).

\section{Outcome variables: cognitive function}

The MSLS neuropsychological test battery comprises 20 individual tests designed to measure a wide range of cognitive abilities, and has been used in multiple studies examining cardiovascular risk factors and cognitive performance (Dore et al., 2008; Elias et al., 2006; Robbins et al., 2005). This battery features four index scores: Visual-Spatial Memory and Organization, Scanning and Tracking, Verbal Episodic Memory, and Working Memory, based on factor analysis (Elias et al., 2006). The Wechsler Adult Intelligence Scale (WAIS) Similarities Test (Lezak, Howieson, \& Loring, 2004), a measure of abstract reasoning, loaded on all composite scores (factors) (Elias et al., 2006) and was thus used separately. A Global Cognition Composite (index) score was derived by averaging the $Z$-scores for all individual tests. The tests used to define each composite are listed and described completely in Supplementary Table 1, which are available online. In addition, the Mini-Mental State Examination (MMSE) (Folstein, Folstein, \& McHugh, 1975), a global measure of mental status widely used in the literature, was also used. All cognitive outcomes are expressed in the same unit of measurement, Z-scores.

\section{Data Analysis}

Independent sample $t$ tests were performed to describe the demographic and health characteristics of the sample, comparing those with reduced HDL levels $(<40 \mathrm{mg} / \mathrm{dL}$ for males and $<50 \mathrm{mg} / \mathrm{dL}$ for females) to those with normal HDL levels ( $\geq 40 \mathrm{mg} / \mathrm{dL}$ for males and $\geq 50 \mathrm{mg} / \mathrm{dL}$ for females). This comparison was made as HDL is our main cholesterol variable of interest.

Levels of HDL, LDL, TC, and triglycerides were further classified into groups based on the National Public Health HDL guidelines (U.S. Department of Health and Human Services, 2001). These groups were as follows: for HDL: $<40$, 40-49, 50-59, $\geq 60 \mathrm{mg} / \mathrm{dL}$; for LDL: <100, 100-129,
130-189, $\geq 190 \mathrm{mg} / \mathrm{dL}$; for TC: $<200,200-239, \geq 240 \mathrm{mg} / \mathrm{dL}$; and for triglycerides: $<150,150-199,200-499, \geq 500 \mathrm{mg} / \mathrm{dL}$.

Multivariate analysis of variance (MANOVA) (a step-down protection procedure) (van der Laan, Dudoit, \& Pollard, 2004) was used to examine relationships between cholesterol concentrations (HDL, LDL, triglycerides, TC) and cognitive performance (Visual-Spatial Memory and Organization, Scanning and Tracking, Verbal Episodic Memory, Working Memory, Similarities, MMSE). All cognitive outcomes were entered into the analyses simultaneously as dependent variables except for the Global Composite score, as the Global Composite score is co-dependent on all the measures except for the MMSE. ANOVA was used to examine relationships between cholesterol concentrations and the Global Composite score. In addition to MANOVA, the Bonferroni procedure was used to protect against multiple comparisons, including the Global Composite, alpha/number of observations where alpha $=0.05$.

Two covariate sets were used: (1) Basic model: adjusted for age, gender, education (years), and ethnicity (African American/other); (2) Extended model: Basic model + BMI $\left(\mathrm{kg} / \mathrm{m}^{2}\right)$, smoking (cigarettes/week), alcohol consumption (ounces/week), systolic blood pressure (mmHg), diabetes (yes/no), CVD (yes/no), cholesterol medications (yes/no), physical activity (MET-minutes/week), depressed mood (CES-D raw score), and apolipoprotein E epsilon 4 (APOE $\varepsilon 4$, yes/no). The covariates included in the extended model were selected based on two considerations: were clinically and theoretically relevant and also related to both the predictor (HDL-cholesterol) and outcome (Global Composite score) (alpha <0.05). Due to the potential importance of APOE $\varepsilon 4$ (Bender \& Raz, 2012; Liu et al., 2010; Notkola et al., 1998) this was also included in the extended model. There were no analyses performed with all lipids in one model because these are co-dependent variables. It is important to present both the basic model and the extended model because the comparisons between the two models informs as to the mediating role of CVD on the cognitive outcomes. A failure to see results for the extended model may be interpreted as evidence that cholesterol is purely a proxy for CVD.

In a final step, logistic regression analyses was performed to obtain a measure of effect size, indicated by the categorical regression coefficient when comparing the highest HDL group ( $\geq 60 \mathrm{mg} / \mathrm{dL}$ ) with the reference (lowest HDL group, $<40 \mathrm{mg} / \mathrm{dL})$.

All statistical analyses were performed with PASW for Windows ${ }^{\circledR}$ version 21.0 software (formerly SPSS Statistics Inc., Chicago, IL).

\section{RESULTS}

\section{Participant Characteristics}

The sample comprised 222 males and 318 females, aged 60 to 98 years (mean, $71.4 \pm 7.6$ years). Table 1 describes the 
Table 1. Demographic and health characteristics of sample $(N=540)$

\begin{tabular}{|c|c|c|c|c|c|c|c|}
\hline \multirow[b]{2}{*}{ Variable } & \multicolumn{2}{|c|}{$\begin{array}{c}\text { All } \\
N=540\end{array}$} & \multicolumn{2}{|c|}{$\begin{array}{l}\text { Low HDL } n=148 \\
<40 \mathrm{mg} / \mathrm{dL} \text { (males) } \\
<50 \mathrm{mg} / \mathrm{dL} \text { (females) }\end{array}$} & \multicolumn{2}{|c|}{$\begin{array}{l}\text { Normal HDL } n=392 \\
\geq 40 \mathrm{mg} / \mathrm{dL} \text { (males) } \\
\geq 50 \mathrm{mg} / \mathrm{dL} \text { (females) }\end{array}$} & \multirow[b]{2}{*}{$p$} \\
\hline & Mean & $S D$ & Mean & $S D$ & Mean & $S D$ & \\
\hline Age (years) & 71.4 & 7.6 & 71.0 & 7.5 & 71.5 & 7.6 & .47 \\
\hline Education (years) & 14.4 & 2.7 & 14.0 & 2.7 & 14.5 & 2.7 & .032 \\
\hline Smoking (cigarettes/week) & 4.8 & 30.0 & 8.6 & 44.9 & 3.3 & 21.8 & .07 \\
\hline Alcohol (oz/week) & 1.5 & 2.6 & 0.44 & 0.98 & 1.9 & 2.9 & $<.001$ \\
\hline BMI $\left(\mathrm{kg} / \mathrm{m}^{2}\right)$ & 28.6 & 5.1 & 30.6 & 5.7 & 27.9 & 4.6 & $<.001$ \\
\hline Total cholesterol (mg/dL) & 201.1 & 39.5 & 184.4 & 39.1 & 207.4 & 37.8 & $<.001$ \\
\hline HDL cholesterol (mg/dL) & 54.6 & 15.3 & 39.5 & 6.2 & 60.3 & 13.8 & $<.001$ \\
\hline LDL cholesterol (mg/dL) & 119.1 & 33.1 & 109.6 & 32.9 & 122.5 & 32.5 & $<.001$ \\
\hline Triglycerides (mg/dL) & 140.0 & 89.1 & 180.5 & 103.5 & 124.7 & 77.9 & $<.001$ \\
\hline Glucose $(\mathrm{mg} / \mathrm{dL})$ & 99.4 & 23.9 & 103.7 & 28.0 & 97.7 & 22.2 & .009 \\
\hline Systolic blood pressure (mmHg) & 137.0 & 20.9 & 139.7 & 20.4 & 136.0 & 21.0 & .07 \\
\hline Diastolic blood pressure $(\mathrm{mmHg})$ & 70.5 & 9.7 & 71.8 & 9.6 & 70.0 & 9.7 & .06 \\
\hline Physical activity (MET mins/wk) & 538 & 383 & 486 & 383 & 560 & 381 & .049 \\
\hline \multirow[t]{2}{*}{ CES-D } & 7.1 & 6.1 & 8.2 & 6.3 & 6.8 & 6.0 & .016 \\
\hline & $N$ & $\%$ & $n$ & $\%$ & $n$ & $\%$ & \\
\hline Gender & & & & & & & .08 \\
\hline Males & 222 & 41.1 & 52 & 35.1 & 170 & 43.4 & \\
\hline Females & 318 & 58.9 & 96 & 64.9 & 222 & 56.6 & \\
\hline Ethnicity & & & & & & & .91 \\
\hline African American & 19 & 3.5 & 5 & 3.4 & 14 & 3.6 & \\
\hline Other & 521 & 96.5 & 143 & 96.6 & 378 & 96.4 & \\
\hline $\mathrm{CVD}^{\mathrm{b}}$ & 112 & 20.7 & 41 & 27.7 & 71 & 18.1 & .014 \\
\hline Diabetes $^{c}$ & 80 & 14.8 & 38 & 25.7 & 42 & 10.7 & $<.001$ \\
\hline Hypertension $^{\mathrm{d}}$ & 390 & 72.2 & 134 & 90.5 & 256 & 65.3 & $<.001$ \\
\hline Cholesterol medication & 199 & 36.9 & 75 & 50.7 & 124 & 31.6 & $<.001$ \\
\hline APOE $\varepsilon 4$ carrier & 136 & 25.4 & 40 & 27.0 & 96 & 24.7 & .59 \\
\hline
\end{tabular}

Note. APOE $\varepsilon 4$ = apolipoprotein E epsilon 4; BMI = body mass index; CES-D = Center for Epidemiologic Studies Depression Scale; CVD = cardiovascular disease; HDL = high density lipoprotein; $\mathrm{LDL}=$ low density lipoprotein; $\mathrm{MET}=$ metabolic equivalent; $\mathrm{SD}=$ standard deviation.

${ }^{a}$ Higher score indicates higher number of depressive symptoms.

${ }^{\mathrm{b}} \mathrm{CVD}$ was defined as present if there was self-reported history of coronary artery disease, myocardial infarction, congestive heart failure, transient ischemic attack, or angina pectoris.

${ }^{c}$ Diabetes was defined as fasting glucose level of $\geq 126 \mathrm{mg} / \mathrm{dL}$, or being treated with anti-diabetic medication.

${ }^{\mathrm{d}}$ Hypertension was defined as $\geq 140 / 90 \mathrm{mmHg}$.

demographic and heath variables of the sample, according to HDL level. Those with reduced HDL (27.4\% of the sample) had slightly fewer years of education, had a higher BMI and fasting plasma glucose levels, and were more likely to have CVD, diabetes, or hypertension, and be on cholesterol medication (all $p<.05$ ).

\section{HDL Levels and Cognition}

The multivariate tests performed as protection against multiple contrasts for multiple outcome variables were statistically significant for both the basic model ( $F$ [Wilks' lambda $]=3.12 ; p<.001)$ and extended models $(F=1.66$; $p=.041)$. Thus we report the results of the univariate analyses for each cognitive outcome.

The covariate adjusted mean (Z-scores) (and $S E$ ) based on multivariable analyses for each cognitive outcome considered separately are presented in Table 2 (basic and extended models). $P$-values are adjusted via the Bonferroni procedure. HDL was significantly and positively associated with the Global Composite score, Visual-Spatial Memory and Organization, Verbal Episodic Memory, Working Memory, Scanning and Tracking, Similarities and the MMSE, with adjustment for age, education, gender, and ethnicity $(p<.05)$. Those with "very good" levels of HDL $(\geq 60 \mathrm{mg} / \mathrm{dL}$ ) had significantly higher scores on the Global Composite, Visual-Spatial Memory and Organization, Working Memory, Scanning and Tracking, Similarities and the MMSE than those with "poor levels" of HDL $(<40 \mathrm{mg} /$ dL) (all $p<.05)$.

Positive relationships between HDL and the Global Composite, Working Memory, and the MMSE remained significant (all $p<.01$ ) with additional adjustment for BMI, smoking, alcohol consumption, systolic blood pressure, 
Table 2. Multivariate adjusted mean ( $z$-scores) (and SE) for each cognitive outcome across increment levels of HDL-cholesterol $(N=540)$

\begin{tabular}{|c|c|c|c|c|c|c|c|c|c|c|c|c|}
\hline \multirow[b]{3}{*}{ Cognitive outcome ${ }^{\mathrm{a}}$} & \multirow[b]{3}{*}{ Model $^{\mathrm{b}}$} & \multicolumn{8}{|c|}{ HDL-cholesterol category } & \multirow[b]{3}{*}{$R^{2 \mathrm{c}}$} & \multirow{3}{*}{$\begin{array}{l}\text { Effect } \\
\text { size }^{\mathrm{f}}\end{array}$} & \multirow{3}{*}{$p$ linear } \\
\hline & & \multicolumn{2}{|c|}{$\begin{array}{c}\text { HDL }<40 \mathrm{mg} / \mathrm{dL} \\
\text { Poor, } n=76\end{array}$} & \multicolumn{2}{|c|}{$\begin{array}{l}\text { HDL } 40-49 \mathrm{mg} / \mathrm{dL} \\
\quad \text { Fair, } n=162\end{array}$} & \multicolumn{2}{|c|}{$\begin{array}{l}\text { HDL } 50-59 \mathrm{mg} / \mathrm{dL} \\
\quad \text { Good, } n=121\end{array}$} & \multicolumn{2}{|c|}{$\begin{array}{c}\text { HDL } \geq 60 \mathrm{mg} / \mathrm{dL} \\
\text { Very good, } n=181\end{array}$} & & & \\
\hline & & $M$ & $S E$ & $M$ & $S E$ & $M$ & $S E$ & $M$ & $S E$ & & & \\
\hline \multirow[t]{2}{*}{ Global Composite } & Basic & -.324 & .094 & $-.019^{\mathrm{d}}$ & .064 & -.099 & .072 & $.220^{\mathrm{de}}$ & .061 & .367 & 0.54 & $<.001$ \\
\hline & Extended & -.230 & .101 & -.026 & .066 & -.100 & .075 & $.178^{\mathrm{de}}$ & .068 & .396 & 0.41 & .006 \\
\hline \multirow[t]{2}{*}{ Visual-Spatial Memory } & Basic & -.144 & .099 & -.061 & .067 & -.105 & .077 & $.183^{\mathrm{de}}$ & .065 & .294 & 0.33 & .015 \\
\hline & Extended & -.086 & .106 & -.059 & .069 & -.105 & .080 & .173 & .072 & .324 & 0.26 & .10 \\
\hline \multirow[t]{2}{*}{ Verbal Memory } & Basic & -.177 & .109 & -.036 & .074 & -.101 & .085 & .175 & .071 & .145 & 0.35 & .019 \\
\hline & Extended & -.110 & .122 & -.063 & .079 & -.086 & .091 & .130 & .082 & .155 & 0.24 & .17 \\
\hline \multirow{2}{*}{ Working Memory } & Basic & -.452 & .109 & $.025^{\mathrm{d}}$ & .074 & -.115 & .085 & $.237^{\mathrm{d}}$ & .071 & .152 & 0.69 & $<.001$ \\
\hline & Extended & -.400 & .120 & $.011^{\mathrm{d}}$ & .078 & -.123 & .090 & $.192^{\mathrm{d}}$ & .081 & .157 & 0.59 & .001 \\
\hline \multirow[t]{2}{*}{ Scanning Tracking } & Basic & -.290 & .097 & $.037^{\mathrm{d}}$ & .066 & -.001 & .075 & $.088^{\mathrm{d}}$ & .063 & .330 & 0.38 & .004 \\
\hline & Extended & -.195 & .104 & .033 & .068 & .006 & .078 & .060 & .070 & .348 & 0.26 & .09 \\
\hline \multirow[t]{2}{*}{ Similarities } & Basic & -.287 & .102 & -.030 & .069 & -.080 & .079 & $.198^{\mathrm{de}}$ & .067 & .257 & 0.49 & $<.001$ \\
\hline & Extended & -.124 & .112 & .009 & .073 & -.086 & .084 & .107 & .076 & .267 & 0.23 & .20 \\
\hline \multirow[t]{2}{*}{ MMSE } & Basic & -.430 & .106 & $-.039^{\mathrm{d}}$ & .072 & $-.032^{\mathrm{d}}$ & .082 & $.237^{\mathrm{de}}$ & .069 & .198 & 0.67 & $<.001$ \\
\hline & Extended & -.256 & .113 & -.002 & .074 & -.065 & .085 & $.195^{\mathrm{d}}$ & .076 & .209 & 0.45 & .006 \\
\hline
\end{tabular}

Notes. $\mathrm{HDL}=$ high-density lipoprotein; MMSE $=$ Mini-Mental State Examination.

${ }^{a}$ ANOVA performed for Global Composite score; MANOVA included: Visual-Spatial Memory, Verbal Memory, Working Memory, Scanning Tracking, Similarities, and MMSE.

${ }^{\mathrm{b}}$ Basic model: adjusted for age, education, gender, ethnicity; Extended model: adjusted for Basic + BMI, smoking, alcohol, systolic blood pressure, diabetes, CVD, cholesterol medications, physical activity, CES-D and APOE $\varepsilon 4$.

${ }^{\mathrm{c}}$ Adjusted $\mathrm{R}^{2}$ for multiple comparisons (Bonferroni).

$\mathrm{d}_{\text {significantly different from HDL }<40 \mathrm{mg} / \mathrm{dL} \text { group. }}$

e significantly different from HDL $50-59 \mathrm{mg} / \mathrm{dL}$ group.

$\mathrm{f}$ effect size is the categorical regression coefficient obtained from logistic regression analyses, comparing the highest HDL group $(\geq 60 \mathrm{mg} / \mathrm{dL})$ with the reference (lowest HDL group, $<40 \mathrm{mg} / \mathrm{dL}$ ).

diabetes, CVD, cholesterol medications, physical activity, depressed mood, and APOE $\varepsilon 4$ status. With full adjustment, those with HDL levels of $60 \mathrm{mg} / \mathrm{dL}$ or higher, performed significantly better on the Global score, tasks of Working Memory, and the MMSE, than those with HDL levels of less than $40 \mathrm{mg} / \mathrm{dL}$ (all $p<.05$ ). All $p$-values reported are based on the Bonferroni adjustment, $p /$ the number of cognitive outcomes.

\section{LDL, TC, Triglyceride Levels, and Cognition}

LDL, TC, and triglyceride levels were unrelated to cognitive function in basic and extended models. The multivariate test results (extended model) were as follows: TC: $F=0.63$, $p=.82 ;$ LDL: $F=1.05, \quad p=.40 ;$ and triglycerides: $F=1.20, p=.26$.

\section{Sensitivity Analysis}

Two sensitivity analyses were performed, examining the relationship between two interaction terms with cognitive function (Global Composite score): (1) HDL $\times$ age (in years), and (2) APOE $\varepsilon 4$ (yes/no) $\times$ HDL. Neither of these interaction terms was associated with the Global cognitive composite score (HDL $\times$ age: $p=0.35$; APOE $\varepsilon 4 \times$ HDL: $p=.40)$.

\section{DISCUSSION}

High density lipoprotein was positively associated with multiple measures of cognitive performance in participants aged 60 years or more. With adjustment for all the basic covariates, cardiovascular risk factors and depressed mood, HDL levels were significantly related to higher levels of mean cognitive functioning in Working Memory, general global cognitive ability (Global Composite score) and general mental status (MMSE). There were no associations observed between concentrations of LDL, TC, or triglycerides and any measure of cognitive function for the basic model or the extended model with cardiovascular covariates.

Our interpretation of these findings is consistent with other studies of systemic risk factors (Waldstein \& Elias, 2014), whereby HDL is positively influencing general cognitive performance. However, working memory performance was, among the other cognitive abilities, of particular importance to overall cognitive function. The present findings with regard to HDL and memory function are consistent with other studies (Reynolds et al., 2010; Singh-Manoux et al., 2008) in terms of a positive relation between HDL and memory. Singh-Manoux et al. (2008) only assessed short term verbal memory using one test, but found that low HDL-cholesterol levels were associated with higher odds of verbal memory deficit. Reynolds et al. (2010) assessed verbal and spatial 
abilities, working memory, and perceptual speed and found that higher concentrations of HDL-cholesterol (and lower triglycerides) predicted better maintenance of verbal ability and perceptual speed, but in women only. In the present study, there was a significant positive association between HDL and the Verbal Memory composite in the basic model, but significance was lost after full adjustment for the cardiovascular risk factors and disease variables. In contrast to Singh-Manoux et al. (2008), we used a composite of scores measuring verbal ability, and the tests were not the same as those used in either investigation above (Reynolds et al., 2010; Singh-Manoux et al., 2008). Differences in sample characteristics may also contribute to the disparate findings. For example, the mean age of participants in these two studies at baseline was slighter younger (50-55 years) than in the present study. Given issues of test purity (Rabbitt, 1997), further studies examining what kind of memory is influenced by HDL would be improved by indexing cognitive domains using more than one test measure (Elias, Goodell, \& Dore, 2012).

Thus, with adjustment for basic covariates, several significant associations were seen, but many fewer remained statistically significant with additional adjustment for the cardiovascular risk factors and CVD. Based on these data, we infer that HDL is not just a proxy for the absence of cardiovascular risk or disease when the outcomes are global cognition, global MMSE and the Working Memory composite. For the extended (cardiovascular risk) model, $\mathrm{R}^{2}$ values for the Global Composite score, MMSE, and Working Memory were $0.40,0.21$, and 0.16 , respectively; thus less of the variance in cognition was explained by a specific domain, Working Memory, as compared to global cognitive ability or the MMSE. Magnitude of effect is reflected in the differences between means for the highest and lowest HDL groups (shown in Table 2). Effect sizes for the Global Composite, MMSE, and Working Memory (extended models) were $Z=0.41,0.45$, and 0.59 , respectively. These are medium to large effect sizes, and have significant implications for cognitive functioning on a population level.

The positive relations between HDL and cognitive function are consistent with the mechanisms that relate lipids to brain and cerebrovascular disease. Thus it is biologically plausible that over 60 years of age, higher levels of HDL are related in a positive manner to global cognitive performance.

Our study did not find any associations between LDL and cognitive performance in persons over 60 years of age, with adjustment for demographic factors or with the addition of cardiovascular risk and disease variables. Previous studies conducted with the same age groups have shown no associations (Reitz et al., 2005), positive associations (Henderson, Guthrie, \& Dennerstein, 2003), and negative associations (Muldoon et al., 1997; Yaffe et al., 2002). A more recent extensive, comprehensive review reflected the same pattern of inconsistencies among findings in the general literature (Muldoon \& Conklin, 2014).

Our study did not find any associations between triglycerides and cognitive performance in persons over 60 years of age. No significant associations were found between triglycerides and verbal memory performance in the Whitehall II study (Singh-Manoux et al., 2008), while lower triglycerides predicted better verbal ability and perceptual speed in women in the Swedish Adoption Twin Study of Aging (Reynolds et al., 2010), and better performance on WAIS scores in another (Muldoon et al., 1997). Differences in methods and samples may contribute to these discrepancies in findings. With regard to the null findings in the present study, it may be speculated that as persons become older they fall into the survivor category where any adverse effects of LDL or triglycerides may be less likely to be observed, and such "surviving" individuals may be less susceptible to disease and impairment.

Similarly, the null findings with regard to TC and cognition in persons 60 years and older in the present study supports the speculation that TC becomes less important to cognition once one survives to age 60 . These null finding are consistent with the recent review by Anstey et al. (2008), who concluded that little evidence supports an association between late-life TC and AD, or dementia. Furthermore, our data on HDL offer an explanation for earlier Framingham Heart Study findings (Elias et al., 2005), in which positive associations between TC and multiple cognitive abilities were observed. Only TC data were available in the Framingham Study and, therefore, it is not possible to determine to what extent positive relations between HDL and cognitive functioning may have influenced this result.

Lifestyle and behavioral factors that influence cholesterol metabolism, as well as cognitive function and the risk of dementia, such as diet, may also help to explain the present findings. Those with normal HDL levels were leaner, smoked less and undertook more physical activity. Poor dietary habits, and high dietary fat intake in particular, have been associated with lower cognitive functioning in elderly samples (Kalmijn, Feskens, Launer, \& Kromhout, 1997; Ortega et al., 1997), although other demographic or premorbid factors, such as intelligence or socioeconomic factors, may at least in part explain these findings.

\section{Strengths and Limitations}

The study was cross-sectional, which does not allow any conclusions regarding a causal relationship between cholesterol levels and cognitive performance. We elected to examine whether cholesterol levels were associated with cognitive performance in an older age range, which also precludes conclusions about such relationships in younger persons. The generalizabilty of the findings may also be limited as a function of the low proportion of ethnic minorities in the study sample.

Our study adds to the literature by examining other cognitive abilities in addition to memory, including a comprehensive number of potential confounders, and using a communitybased and dementia-free sample. It is important to examine cognition in individuals without dementia, as the disease itself may modify cholesterol levels (Solomon et al., 2007). 
We excluded persons with prevalent stroke, dementia and on kidney dialysis. We also adjusted for multiple cardiovascular risk factors, and other potential confounders, including the use of cholesterol medications. Most importantly, and expanding upon previous research, we have measured cognitive performance using an extensive neuropsychological test battery, including multiple cognitive domains and the MMSE.

\section{CONCLUSIONS AND IMPLICATIONS}

Higher concentrations of HDL-cholesterol were related to better Working Memory performance, global cognitive ability, and general mental status. While the adverse influence of "bad cholesterol" has received much attention, there has been much less research on "good cholesterol" and this study indicates that more is necessary. This study and others suggest a focus on HDL, LDL, and triglycerides is much more useful than a focus on TC alone.

Maintaining high levels of HDL are indicated to serve a protective effect against neurodegenerative and vascular diseases. Strategies such as the modification of lifestyle behaviors that may increase HDL levels, such as consuming a healthy, low fat diet and undertaking regular physical activity should continue to be recommended. Our understanding may be enhanced by future longitudinal studies examining relations between multiple cognitive abilities and the different cholesterols, especially with the identification of multiple domains of ability indexed by more than a single test (Elias et al., 2012).

\section{ACKNOWLEDGMENTS}

This study was supported in part by National Heart, Lung, and Blood Institute (grant numbers R01HL67358, R01HL81290); by the National Institute on Aging (grant R01AG03055); and by a Sidney Sax Research Fellowship (National Health and Medical Research Council, Australia, G.E.C., grant number APP1054567). The authors declare no conflicts of interest.

\section{Supplementary material}

To view supplementary material for this article, please visit http://dx.doi.org/10.1017/S1355617714000885

\section{REFERENCES}

Anstey, K.J., Lipnicki, D.M., \& Low, L.F. (2008). Cholesterol as a risk factor for dementia and cognitive decline: A systematic review of prospective studies with meta-analysis. American Journal of Geriatric Psychiatry, 16, 343-354. doi: 10.1097/ JGP.0b013e31816b72d4

Bender, A.R., \& Raz, N. (2012). Age-related differences in episodic memory: A synergistic contribution of genetic and physiological vascular risk factors. Neuropsychology, 26, 442-450. doi: 10.1037/a0028669

Benton, D. (1995). Do low cholesterol levels slow mental processing? Psychosomatic Medicine, 57, 50-53.
Desmond, D.W., Tatemichi, T.K., Paik, M., \& Stern, Y. (1993). Risk factors for cerebrovascular disease as correlates of cognitive function in a stroke-free cohort. Archives of Neurology, 50, 162-166.

Dietschy, J.M., \& Turley, S.D. (2004). Cholesterol metabolism in the central nervous system during early development and in the mature animal. Journal of Lipid Research, 45, 1375-1397. doi: 10.1194/jlr.r400004

Dore, G.A., Elias, M.F., Robbins, M.A., Budge, M.M., \& Elias, P.K. (2008). Relation between central adiposity and cognitive function in the Maine-Syracuse Study: Attenuation by physical activity. Annals of Behavioral Medicine, 35, 341-350. doi: 10.1007/ s12160-008-9038-7

Elias, M.F., Goodell, A.L., \& Dore, G.A. (2012). Hypertension and cognitive functioning: A perspective in historical context. Hypertension, 60, 260-268. doi: 10.1161/HYPERTENSIONAHA. 111.186429

Elias, M.F., Robbins, M.A., Budge, M.M., Abhayaratna, W.P., Dore, G.A., \& Elias, P.K. (2009). Arterial pulse wave velocity and cognition with advancing age. Hypertension, 53, 668-673. doi: HYPERTENSIONAHA.108.126342 [pii] 10.1161/ HYPERTENSIONAHA.108.126342

Elias, M.F., Robbins, M.A., Budge, M.M., Elias, P.K., Brennan, S.L., Johnston, C., ... Bates, C.J. (2006). Homocysteine, folate, and vitamins B6 and B12 blood levels in relation to cognitive performance: The Maine-Syracuse study. Psychosomatic Medicine, 68, 547-554. doi: 68/4/547 [pii]10.1097/01.psy.0000221380. 92521.51

Elias, P.K., Elias, M.F., D’Agostino, R.B., Sullivan, L.M., \& Wolf, P.A. (2005). Serum cholesterol and cognitive performance in the Framingham Heart Study. Psychosomatic Medicine, 67, 24-30. doi: 67/1/24 [pii] 10.1097/01.psy.0000151745.67285.c2

Elsoe, S., Ahnstrom, J., Christoffersen, C., Hoofnagle, A.N., Plomgaard, P., Heinecke, J.W., ... Nielsen, L.B. (2012). Apolipoprotein $\mathrm{M}$ binds oxidized phospholipids and increases the antioxidant effect of HDL. Atherosclerosis, 221, 91-97. doi: 10.1016/j.atherosclerosis.2011.11.031

Felix-Redondo, F.J., Grau, M., \& Fernandez-Berges, D. (2013). Cholesterol and cardiovascular disease in the elderly. Facts and gaps. Aging and Disease, 4, 154-169.

Folstein, M.F., Folstein, S.E., \& McHugh, P.R. (1975). "Minimental state". A practical method for grading the cognitive state of patients for the clinician. Journal of Psychiatric Research, 12, 189-198. doi: 0022-3956(75)90026-6 [pii]

Henderson, V.W., Guthrie, J.R., \& Dennerstein, L. (2003). Serum lipids and memory in a population based cohort of middle age women. Journal of Neurology Neurosurgery, and Psychiatry, 74, 1530-1535. doi: 10.1136/jnnp.74.11.1530

Hillbrand, M., \& Spitz, R.T., (Eds.). (1997). Lipids, health, and behavior. Washington, DC: American Psychological Association.

Kalmijn, S., Feskens, E.J., Launer, L.J., \& Kromhout, D. (1996). Cerebrovascular disease, the apolipoprotein e4 allele, and cognitive decline in a community-based study of elderly men. Stroke, 27, 2230-2235.

Kalmijn, S., Feskens, E.J., Launer, L.J., \& Kromhout, D. (1997). Polyunsaturated fatty acids, antioxidants, and cognitive function in very old men. American Journal of Epidemiology, 145, 33-41.

Karlamangla, A.S., Singer, B.H., Reuben, D.B., \& Seeman, T.E. (2004). Increases in serum non-high-density lipoprotein cholesterol may be beneficial in some high-functioning older adults: MacArthur studies of successful aging. Journal of the 
American Geriatrics Society, 52, 487-494. doi: 10.1111/j.15325415.2004.52152.x

Koudinov, A.R., \& Koudinova, N.V. (2001). Essential role for cholesterol in synaptic plasticity and neuronal degeneration. FASEB Journal, 15, 1858-1860.

Kroke, A., Klipstein-Grobusch, K., Voss, S., Moseneder, J., Thielecke, F., Noack, R., \& Boeing, H. (1999). Validation of a self-administered food-frequency questionnaire administered in the European Prospective Investigation into Cancer and Nutrition (EPIC) Study: Comparison of energy, protein, and macronutuient intakes estimated with the doubly labeled water, urinary nitrogen, and repeated 24-h dietary recall methods. American Journal of Clinical Nutrition, 70, 439-447.

Lezak, M.D., Howieson, D.B., \& Loring, D.W. (2004). Neuropsychological assessment (4th ed.). New York, NY: Oxford University Press.

Liu, F., Pardo, L.M., Schuur, M., Sanchez-Juan, P., Isaacs, A., Sleegers, K., ... van Duijn, C.M. (2010). The apolipoprotein E gene and its age-specific effects on cognitive function. Neurobiology of Aging, 31, 1831-1833. doi: 10.1016/j.neurobiolaging.2008.09.015

Liu, J., Zeng, F.-F., Liu, Z.-M., Zhang, C.-X., Ling, W.-h., \& Chen, Y.-M. (2013). Effects of blood triglycerides on cardiovascular and all-cause mortality: A systematic review and meta-analysis of 61 prospective studies. Lipids in Health and Disease, 12, 159. doi: 10.1186/1476-511x-12-159

McKhann, G., Drachman, D., Folstein, M., Katzman, R., Price, D., \& Stadlan, E.M. (1984). Clinical diagnosis of Alzheimer's disease: Report of the NINCDS-ADRDA Work Group under the auspices of Department of Health and Human Services Task Force on Alzheimer's Disease. Neurology, 34, 939-944.

Mielke, M.M., Xue, Q.L., Zhou, J., Chaves, P.H., Fried, L.P., \& Carlson, M.C. (2008). Baseline serum cholesterol is selectively associated with motor speed and not rates of cognitive decline: The Women's Health and Aging Study II. Journals of Gerontology. Series A: Biological Sciences and Medical Sciences, 63, 619-624.

Muldoon, M.F., \& Conklin, S.M. (2014). Effects of cholesterol and n-3 fatty acids on cognitive functioning, decline and dementia. In S. Waldstein \& M.F. Elias (Eds.), Neuropsychology of cardiovascular disease (2nd ed.). New York: Taylor and Francis.

Muldoon, M.F., Ryan, C.M., Matthews, K.A., \& Manuck, S.B. (1997). Serum cholesterol and intellectual performance. Psychosomatic Medicine, 59, 382-387.

Nofer, J.R., Kehrel, B., Fobker, M., Levkau, B., Assmann, G., \& von Eckardstein, A. (2002). HDL and arteriosclerosis: Beyond reverse cholesterol transport. Atherosclerosis, 161, 1-16. doi: 10.1016/s0021-9150(01)00651-7

Notkola, I.L., Sulkava, R., Pekkanen, J., Erkinjuntti, T., Ehnholm, C., Kivinen, P., ... Nissinen, A. (1998). Serum total cholesterol, apolipoprotein E epsilon 4 allele, and Alzheimer's disease. Neuroepidemiology, 17, 14-20.

Ortega, R.M., Requejo, A.M., Andres, P., Lopez-Sobaler, A.M., Quintas, M.E., Redondo, M.R., ... Rivas, T. (1997). Dietary intake and cognitive function in a group of elderly people. American Journal of Clinical Nutrition, 66, 803-809.

Rabbitt, P.M.A. (1997). Methodology of frontal and executive function. East Sussex: Psychology Press.

Radloff, L.S. (1977). The CES-D Scale: A self-report depression scale for research in the general population. Applied Psychological Measurement, 1, 385-401.

Reitz, C., Luchsinger, J., Tang, M.X., Manly, J., \& Mayeux, R. (2005). Impact of plasma lipids and time on memory performance in healthy elderly without dementia. Neurology, 64, 1378-1383.
Reynolds, C.A., Gatz, M., Prince, J.A., Berg, S., \& Pedersen, N.L. (2010). Serum lipid levels and cognitive change in late life. Journal of the American Geriatrics Society, 58, 501-509. doi: 10.1111/j.1532-5415.2010.02739.x

Robbins, M.A., Elias, M.F., Elias, P.K., \& Budge, M.M. (2005). Blood pressure and cognitive function in an African-American and a Caucasian-American sample: The Maine-Syracuse Study. Psychosomatic Medicine, 67, 707-714. doi: 67/5/707 [pii] 10.1097/01.psy.0000171164.50990.80

Romas, S.N., Tang, M.X., Berglund, L., \& Mayeux, R. (1999). APOE genotype, plasma lipids, lipoproteins, and $\mathrm{AD}$ in community elderly. Neurology, 53, 517-521.

Schreurs, B.G. (2010). The effects of cholesterol on learning and memory. Neuroscience and Biobehavioral Reviews, 34, 1366-1379. doi: 10.1016/j.neubiorev.2010.04.010

Silbernagel, G., Schoettker, B., Appelbaum, S., Scharnagl, H., Kleber, M.E., Grammer, T.B., ... Maerz, W. (2013). High-density lipoprotein cholesterol, coronary artery disease, and cardiovascular mortality. European Heart Journal, 34, 3563-3571. doi: 10.1093/eurheartj/eht343

Singh-Manoux, A., Gimeno, D., Kivimaki, M., Brunner, E., \& Marmot, M.G. (2008). Low HDL cholesterol is a risk factor for deficit and decline in memory in midlife - The Whitehall II study. Arteriosclerosis, Thrombosis, and Vascular Biology, 28, 1556-1562. doi: 10.1161/atvbaha.108.163998

Solomon, A., Kareholt, I., Ngandu, T., Winblad, B., Nissinen, A., Tuomilehto, J., ... Kivipelto, M. (2007). Serum cholesterol changes after midlife and late-life cognition: Twenty-one-year follow-up study. Neurology, 68, 751-756. doi: 10.1212/01. wnl.0000256368.57375.b7

Swan, G.E., Larue, A., Carmelli, D., Reed, T.E., \& Fabsitz, R.R. (1992). Decline in cognitive performance in aging twins heritability and biobehavioral predictors from the National Heart Lung and Blood Institute Twin Study. Archives of Neurology, 49, 476-481.

Tehrani, D.M., Gardin, J.M., Yanez, D., Hirsch, C.H., Lloyd-Jones, D.M., Stein, P.K., \& Wong, N.D. (2013). Impact of inflammatory biomarkers on relation of high density lipoproteincholesterol with incident coronary heart disease: Cardiovascular Health Study. Atherosclerosis, 231, 246-251. doi: 10.1016/j. atherosclerosis.2013.08.036

U.S. Department of Health and Human Services. (2001). ATP III Guidelines At-A-Glance Quick Desk Reference. Retrieved from https://www.nhlbi.nih.gov/guidelines/cholesterol/atglance.pdf

Vaisar, T., Pennathur, S., Green, P.S., Gharib, S.A., Hoofnagle, A.N., Cheung, M.C., ... Heinecke, J.W. (2007). Shotgun proteomics implicates protease inhibition and complement activation in the antiinflammatory properties of HDL. Journal of Clinical Investigation, 117, 746-756. doi: 10.1172/jc126206

van den Kommer, T.N., Dik, M.G., Comijs, H.C., Jonker, C., \& Deeg, D.J. (2012). Role of lipoproteins and inflammation in cognitive decline: Do they interact? Neurobiology of Aging, 33, 196 e191-e112. doi: 10.1016/j.neurobiolaging.2010.05.024

van der Laan, M.J., Dudoit, S., \& Pollard, K.S. (2004). Multiple testing. Part II. Step-down procedures for control of the familywise error rate. Statistical Applications in Genetics and Molecular Biology, 3, Article14 doi: 10.2202/1544-6115.1041

van Vliet, P. (2012). Cholesterol and late-life cognitive decline. Journal of Alzheimer's Disease, 30(Suppl 2), S147-S162. doi: 10.3233/jad-2011-111028

van Vliet, P., Westendorp, R.G., van Heemst, D., de Craen, A.J., \& Oleksik, A.M. (2010). Cognitive decline precedes late-life 
longitudinal changes in vascular risk factors. Journal of Neurology Neurosurgery and Psychiatry, 81, 1028-1032. doi: 10.1136/jnnp.2009.182519

Wada, T., Matsubayashi, K., Okumiya, K., Kimura, S., Osaka, Y., Doi, Y., \& Ozawa, T. (1997). Lower serum cholesterol level and later decline in cognitive function in older people living in the community, Japan. Journal of the American Geriatrics Society, 45, 1411-1412.

Waldstein, S.R., \& Elias, M.F. (Eds.). (2001). Neuropsychology of cardiovascular disease. Mahwah, NJ: Lawrence Erlbaum Associates.

Waldstein, S.R., \& Elias, M.F. (Eds.). (2014). Neuropsychology of cardiovascular disease (2nd ed.). New York: Taylor \& Francis (in press).

Wolf, H., Hensel, A., Arendt, T., Kivipelto, M., Winblad, B., \& Gertz, H.J. (2004). Serum lipids and hippocampal volume: The link to Alzheimer's disease? Annals of Neurology, 56, 745-748. doi: 10.1002/ana.20289
Yaffe, K., Barrett-Connor, E., Lin, F., \& Grady, D. (2002). Serum lipoprotein levels, statin use, and cognitive function in older women. Archives of Neurology, 59, 378-384.

Yoshitake, T., Kiyohara, Y., Kato, I., Ohmura, T., Iwamoto, H., Nakayama, K., ... et al. (1995). Incidence and risk factors of vascular dementia and Alzheimer's disease in a defined elderly Japanese population: The Hisayama Study. Neurology, 45, 1161-1168.

Zhang, J., Muldoon, M.F., \& McKeown, R.E. (2004). Serum cholesterol concentrations are associated with visuomotor speed in men: Findings from the third National Health and Nutrition Examination Survey, 1988-1994. American Journal of Clinical Nutrition, 80, 291-298.

Zimetbaum, P., Frishman, W.H., Ooi, W.L., Derman, M.P., Aronson, M., Gidez, L.I., \& Eder, H.A. (1992). Plasma lipids and lipoproteins and the incidence of cardiovascular disease in the very elderly. The Bronx Aging Study. Arteriosclerosis and Thrombosis, 12, 416-423. 